\title{
Canadian Thoracic Society Asthma Committee commentary on long-acting beta-2 agonist use for asthma in Canada
}

\author{
M Diane Lougheed MD MSc (Chair) ${ }^{1}$, Catherine Lemiere MD², Sharon Dell MD ${ }^{3}$, Francine Ducharme MD $^{2}$, \\ J Mark FitzGerald $\mathrm{MD}^{4}$, Richard Leigh $\mathrm{MD} \mathrm{PhD}^{5}$, Chris Licskai $\mathrm{MD}^{6}$, Brian $\mathrm{H}_{\text {Rowe }} \mathrm{MD} \mathrm{MSc}{ }^{7}$, Dennis Bowie $\mathrm{MD}^{8}$, \\ Allan Becker $\mathrm{MD}^{9}$, Louis-Philippe Boulet $\mathrm{MD}^{10}$
}

$\mathrm{T}$ he Canadian Thoracic Society (CTS) Asthma Committee has reviewed the announcement made February 18, 2010, by the United States Food and Drug Administration (FDA) regarding new safety controls and labelling requirements for long-acting beta-2 agonists (LABAs) for asthma in the United States. The purpose of the present commentary is to put the FDA's recommendation in context for CTS members, particularly in light of the new 2010 CTS Asthma Management Continuum published in the January/February issue of the Canadian Respiratory Journal (1).

The FDA's recommendations appear to be based on the Salmeterol Multi-Centre Asthma Research Trial (SMART) (2), the Salmeterol Nationwide Surveillance study (SNS) and a metaanalysis of 110 studies conducted as part of the 2008 FDA Pulmonary Allergy Drug Advisory Committee (PADAC) review of the safety of LABAs, which focused on their use in pediatric asthma in particular. Safety concerns related to an observed increased risk of severe asthma exacerbations requiring hospitalization in children and adults, and increased risk of death in some patients with asthma in these studies.

The 2010 CTS Asthma Management Continuum and Consensus Summary (1) is congruent with the FDA's recommendations. Ever since LABAs were introduced in Canada, the 1996 Canadian Asthma Consensus Conference (3), subsequent updates (4-6), a perspective on LABAs (7), an evidence-based review (8) and the most recent Consensus Summary (1) have all emphasized the following:

- LABAs should never be used alone (as monotherapy) for asthma in any age group;

- LABAs should only be used as add-on therapy to an antiinflammatory controller (such as an inhaled corticosteroid [ICS], ideally, in the same inhaler device) in any age group;

- All patients and caregivers should receive self-management education, including the role and proper use of medications, and a written action plan; and

- All patients with asthma should receive regular medical review, and that asthma controller therapy should be adjusted to the least amount required to maintain control.

The FDA recognizes the need for and has mandated additional research regarding the safety of LABAs when used, as currently recommended, in combination with controller therapy such as
ICS. Until then, the FDA has deemed that the benefits of LABAs outweigh the potential risk, when used appropriately. Our committee concurs with this recommendation; however, our committee cautions that the FDA recommendation that "LABA be used for the shortest duration possible to achieve control of asthma symptoms and then discontinued" is not evidence based. We identify the safety of this approach as a priority for future research. Moreover, efforts to maintain control using the least amount of medication require supervision by a health care provider.

With respect to the role of LABAs in children and adolescents, the 2010 CTS Asthma Consensus Summary emphasizes the following:

- If a LABA is used in children, a combination inhaler of an ICS plus a LABA is preferred over separate inhalers of each to preclude the use of a LABA without an ICS, which may arise due to adherence issues.

- Use of a single inhaler of budesonide and formoterol for maintenance and relief is only approved for use in individuals 12 years of age and over.

- In children six to 11 years of age:

- ICS should be increased to medium dose before any add-on therapy is considered; and

- use of a LABA should only be considered as add-on therapy for individuals whose asthma remains uncontrolled despite medium-dose ICS. If asthma remains uncontrolled on a medium dose of ICS in this age group, addition of a LABA or leukotriene receptor antagonist (LTRA) are both therapeutic options. There are no head-to-head comparisons between LABAs and LTRAs as add-on therapy in this age group, precluding an evidence-based recommendation regarding which is superior at this time.

- In children 12 years of age and over:

- use of a LABA may be considered as add-on therapy for individuals whose asthma remains uncontrolled despite low-dose ICS. LTRAs are an alternative add-on therapy in this age group as well.

This is a rapidly evolving area of primary research and evidence synthesis. Clinicians are advised to refer to the Canadian Respiratory Journal and the CTS for further updates.

${ }^{1}$ Queen's University, Kingston, Ontario; ${ }^{2}$ University of Montreal, Montreal, Quebec; ${ }^{3}$ University of Toronto, Toronto, Ontario; ${ }^{4}$ University of

British Columbia, Vancouver, British Columbia; ${ }^{5}$ University of Calgary, Calgary, Alberta; ${ }^{6}$ University of Western Ontario, London, Ontario;

${ }^{7}$ University of Alberta, Edmonton, Alberta; ${ }^{8}$ Dalhousie University, Halifax, Nova Scotia; ${ }^{9}$ University of Manitoba, Winnipeg, Manitoba;

${ }^{10}$ Laval University, Quebec City, Quebec

Correspondence: Dr M Diane Lougheed, Division of Respirology, Department of Medicine, Queen's University, 102 Stuart Street, Kingston,

Ontario K7L 2V6. Telephone 613-548-2348, fax 613-549-1459, e-mail mdl@queensu.ca 
ACKNOWLEDGEMENTS: The authors thank the Canadian Lung Association staff Ms Stella Muthuri and Ms Janet Sutherland for their outstanding administrative support. Dr Fitzgerald is a Michael Smith Foundation for Health Research Distinguished Scholar. Dr Rowe is supported by a 21st Century Canada Research Chair in Emergency Airway Diseases from the Government of Canada (Ottawa, Ontario).

SPONSORING ORGANIZATIONS: The Canadian Thoracic Society and the Lung Association.

FUNDING: The Canadian Thoracic Society (CTS) received unrestricted grants to facilitiate the knowledge translation activities of the CTS Asthma Committee from AstraZeneca Canada, GlaxoSmithKline Inc, Merck Frosst Canada and Novartis Pharmaceuticals Canada Inc. None of the sponsors played a role in the collection, review, analysis or interpretation of the scientific literature or in any decisions regarding the key messages presented in this document.

DISCLOSURE OF COMPETING INTERESTS: Collectively, the physicians on the CTS Asthma Committee have on at least on one occasion, acted as consultants for and received research funds and speaker's fees from these pharmaceutical companies.

\section{REFERENCES}

1. Lougheed MD, Lemiere C, Dell SD, et al. Canadian Thoracic Society Asthma Management Continuum - 2010 Consensus Summary for children six years of age and over, and adults. Can Respir J 2010;17:15-24.

2. Nelson HS, Weiss ST, Bleecker ER, et al. The Salmeterol Multicenter Asthma Research Trial: A comparison of usual pharmacotherapy for asthma or usual pharmacotherapy plus salmeterol. Chest 2006;129:15-26.

3. Ernst P, Fitzgerald JM, Spier S. Canadian Asthma Consensus Conference Summary of Recommendations. Can Respir J 1996;3:89-100.

4. Boulet L-P, Becker A, Berube D, et al. Canadian asthma consensus report, 1999. CMAJ 1999;161(11 Suppl):S1-S62.

5. Lemiere C, Bai T, Balter M, et al. Adult Asthma Consensus Guidelines Update 2003. Can Respir J 2004;11(Suppl A):9A-18A.

6. Becker A, Lemiere C, Berube D, et al. Summary of recommendations from the Canadian Asthma Consensus guidelines, 2003. CMAJ 2005;173(6 Suppl):S3-11.

7. Ernst P, McIvor A, Ducharme FM, et al; Canadian Asthma Guidelines Group. Safety and effectiveness of long-acting inhaled beta-agonist bronchodilators when taken with inhaled corticosteroids. Ann Intern Med 2006;145:692-4.

8. Balter MS, Bell AD, Kaplan AG, et al. Management of asthma in adults. CMAJ 2009;181:915-22. 


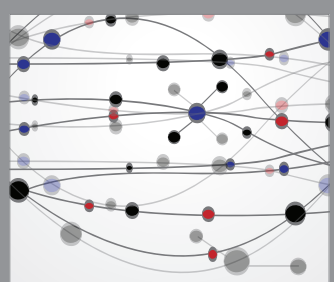

The Scientific World Journal
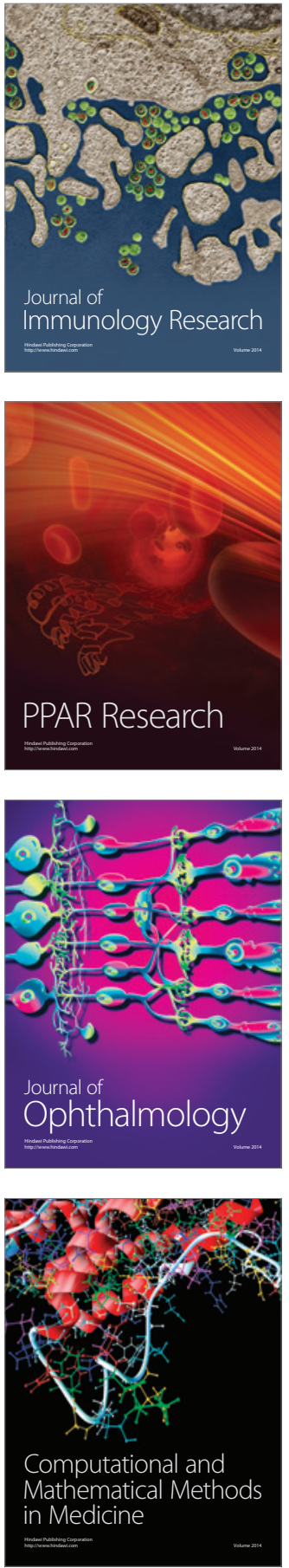

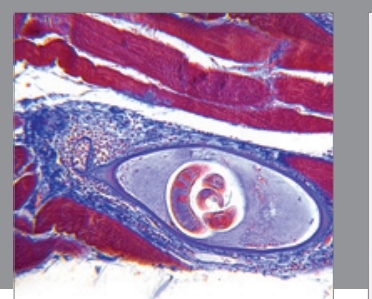

Gastroenterology Research and Practice

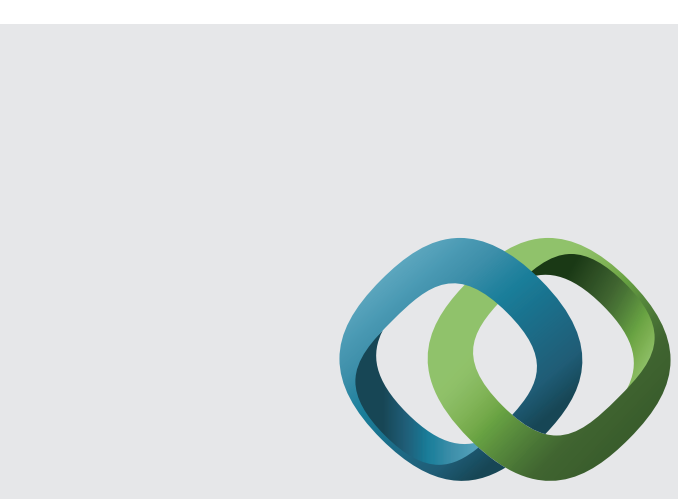

\section{Hindawi}

Submit your manuscripts at

http://www.hindawi.com
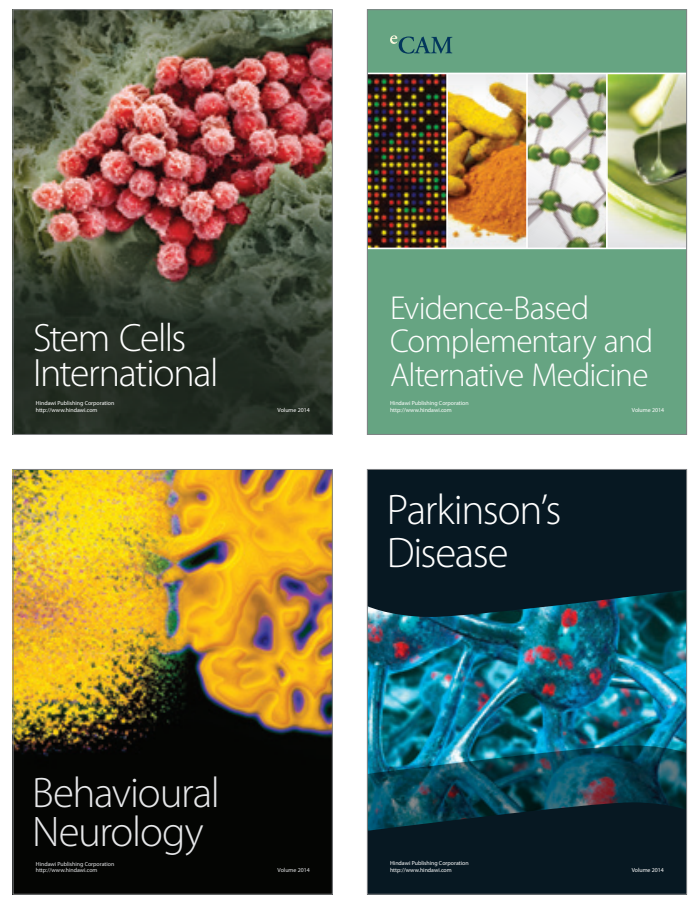
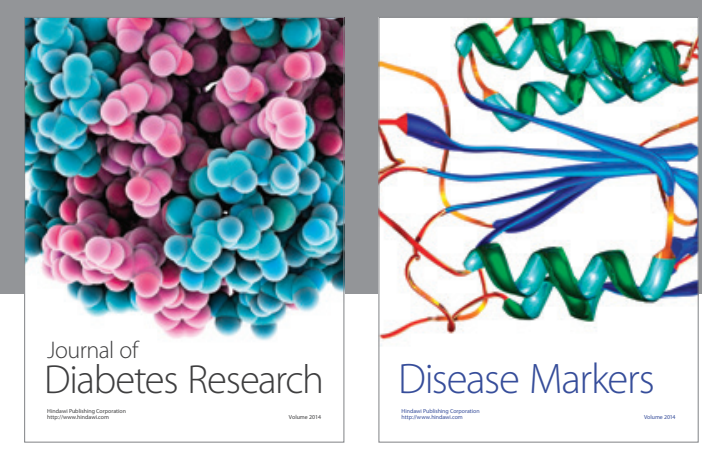

Disease Markers
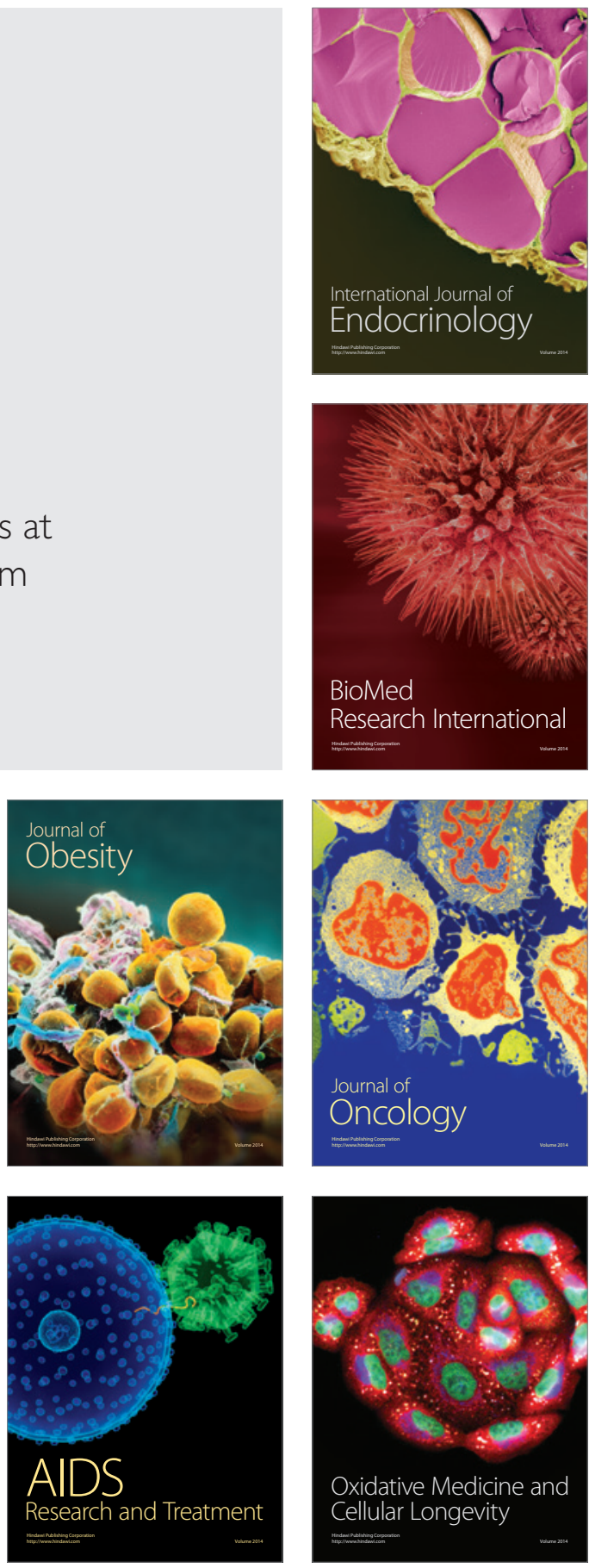